\title{
DISTAL RADIUS FRACTURES- A COMPARATIVE STUDY BETWEEN CONSERVATIVE MANAGEMENT AND EXTERNAL FIXATION
}

\author{
Vaibhav Agrawal ${ }^{1}$, Kumar Rohit ${ }^{2}$ \\ ${ }_{1}^{1}$ Postgraduate Resident, Department of Orthopaedics, Mahatma Gandhi Medical College, Jaipur. \\ 2Senior Resident, Department of Orthopaedics, Mahatma Gandhi Medical College, Jaipur.
}

\begin{tabular}{l}
\hline ABSTRACT \\
BACKGROUND \\
Fracture of the distal radius account for approximately $1 / 6$ of all fractures seen and treated in emergency rooms. Distal radius \\
fractures frequently show intra-articular involvement and comminution. These fractures often are unstable, are difficult to reduce \\
anatomically and are associated with a high prevalence of complications. Restoration of normal alignment and articular congruity \\
after a displaced fracture can be difficult, but it is essential for a good functional result. The principles of treatment for distal radius \\
fractures are anatomical reconstruction, stable fixation and early motion. Closed reduction and plaster casting and JESS fixator is \\
done in most fractures of distal radius, especially stable ones or unstable also. The present study was carried out to study and \\
compare the outcome of conservative method and JESS fixator for distal radius fracture.
\end{tabular}

\section{MATERIALS AND METHODS}

The study was conducted in Mahatma Gandhi Hospital from 31 May 2012 to Nov. 2014. Total 30 cases of both intra- and extraarticular distal end of radius were chosen. The patients were treated either by closed reduction and plaster or closed reduction and external fixator. Thus, there were two groups of 15 patients each chosen randomly, the outcome of both methods and treatment was compared at the end of study on the basis of functional and radiological results according to Gartland and Werley criteria.

\section{RESULTS}

The mechanism of injury in $66.67 \%$ cases was due to fall on outstretched hand. The period of immobilisation in our study ranged between 5 and 6 weeks. In conservative group 10 patients had excellent-to-good results, 2 of them had fair results and 3 had poor results, while in external fixator group 13 patients had excellent-to-good results, 1 of them had fair results and 1 had poor results. By comparing the two groups, the range of movement at 6 months followup did not show any statistical significance, which indicates that both the modalities of treatment brought similar result in long term. The radiological measurements were done and the mean \pm standard deviation was computed. The radial height of $10.15 \pm 1.85$ was noted in Jess group, while Dorsal angle, Radial angle were found to be $3.40 \pm 3.20$ and $17.07 \pm 6.26$ respectively, but the conservative had better results as the radial height came out to be $11.13 \pm 3.44$, while Dorsal angle, Radial angle were $3.86 \pm 3.20,18.13 \pm 4.75$ indicating better results with conservative group. The results were statistically not significant.

\section{CONCLUSION}

Thus, we would like to conclude that external fixation is the treatment of choice in intraarticular fractures of lower end radius.

\section{KEYWORDS}

Distal Radius, JESS Fixator, Colles' Fracture.

HOW TO CITE THIS ARTICLE: Agrawal V, Rohit K. Distal radius fractures - a comparative study between conservative management and external fixation. J. Evolution Med. Dent. Sci. 2017;6(14):1093-1098, DOI: 10.14260/Jemds/2017/237

\section{BACKGROUND}

Fracture of the distal radius account for approximately $1 / 6$ of all fractures seen and treated in emergency rooms.[1,2,3,4,5,6] Distal radius fractures are caused by severe high energy trauma, resulting in intra-articular involvement and comminution.[1,2] These fractures often are unstable, are difficult to reduce anatomically and are associated with a high prevalence of complications.[7] Restoration of normal alignment and articular congruity after a displaced fracture can be difficult, but it is essential for a good functional result.[2,8] Treatment of distal radius fracture is controversial.

Financial or Other, Competing Interest: None.

Submission 20-04-2015, Peer Review 01-02-2017,

Acceptance 08-02-2017, Published 16-02-2017.

Corresponding Author:

Dr. Vaibhav Agrawal,

S/o. Dr. Mahesh Agrawal,

B. N. Gate, Near Kali Ki Bagichi,

Bharatpur, Rajasthan.

E-mail: akash.agrawal1234@gmail.com

DOI: $10.14260 /$ jemds $/ 2017 / 237$

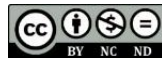

There is no single definitive treatment method that is considered the standard of care. The principles of treatment for distal radius fractures are anatomical reconstruction, stable fixation and early motion. Closed reduction and plaster casting and JESS fixator is done in most fractures of distal radius, especially stable ones or unstable also.[8,7,8,9,10,11] Fractures of the distal radius are not to be underestimated, because even though an anatomical reduction is not indispensable to achieve a good result, but there is a great deal of secondary displacement,[12,13] therefore one should be aware of this possibility bearing in mind that beyond certain values gross radiological abnormalities are significantly associated with fair-to-poor results. It appears that improved anatomical reduction combined with early rehabilitation of wrist function provides very favourable results.[2,14-15]

Aims and Objectives

- To study the incidence, mechanism of injury and classification of fracture distal end of radius.

- To study and compare the functional outcome of fracture of distal radius treated with external fixator and plaster treatment.

- To study complications, merits, demerits of the same. 


\section{MATERIALS AND METHODS}

The study was conducted in Department of Orthopaedics; Mahatma Gandhi Medical College and Hospital from 31 May 2012 to Nov 2014. All cases attending in Orthopaedic Department for treatment of distal radius fracture were seen, of which 30 cases were selected for study. Skeletally mature patients having closed fracture of distal radius without any additional fractures or neurovascular injuries were included in the study only.

On arrival of patient detail history regarding age, sex, mode of injury, days since injury, associated injuries were noted carefully, then x-rays advised - Wrist Joint A-P view, Lateral view. Case selection was done on the criteria of history, clinical examination and radiological (x-ray) examination. Soon after the admission, clinical data were recorded according to the proforma. The diagnosis was based on clinical examination and supported by radiological ( $\mathrm{x}$-ray) examination. The important points considered were -

- Fracture displacement.

- Intra-articular or partial articular involvement.

- Associated ulnar fracture or disruption of the distal radioulnar joint.

- An overall assessment of bone quality and comminution.

\section{According to these Criteria, all Patients were Assigned Randomly in One of the following Two Groups}

1. Conservative: By closed reduction under general anaesthesia or sedation and below elbow POP slab followed by conversion to below elbow cast one week later.

2. Operative: AO distractor was applied in this group.

\section{Operative Procedure for AO Distractor}

Operative procedure was done in O.T. under all aseptic precautions after taking due written informed consent of the patient. Most of the procedures were done under supraclavicular block (regional anaesthesia) and occasionally general anaesthesia. The patient taken on standard orthopaedic table with side hand rest in supine position. After painting and draping, traction was applied to reduce the fracture to optimum position; $3.5 \mathrm{~mm}$ Schanz pins were put in radius at musculotendinous junction after pre-drilling and by semi-open method to avoid entrapment of tendons in Schanz pin. They were drilled at $20^{\circ}$ dorso-lateral position using the distracter clamp as a guide. Similarly, $2.5 \mathrm{~mm}$ Schanz pins were drilled in $2^{\text {nd }}$ and $3^{\text {rd }}$ metacarpals. Special care was taken to displace 1st dorsal interossei ventrally and keeping fingers completely flexed to avoid tendon entrapment. Distraction was used for finer adjustments reduction was checked on $\mathrm{C}$-arm and by $\mathrm{AP}$ and lateral x-rays. Pin tract dressing done.

\section{Conservative Treatment}

Patients were treated conservatively, were taken into 0.T. under general anaesthesia. Reduction was done with wrist in palmar flexion and ulnar deviation. The adequacy of the reduction was checked under $\mathrm{C}$-arm and then below elbow POP slab was given. After 7 - 10 days another check x-ray was taken and found satisfactory, then completion of cast was done after a total period of 6 weeks. Plaster was removed and physiotherapy was done.

\section{RESULTS}

\section{Observations}

In the present study, 30 cases of fractures of distal radius treated by closed reduction with cast method and Jess fixator. The age incidence ranged from 21 yrs. to 50 yrs. with mean of average age group first was 36.3 years. Average age group second was 35.3 years. Male-to-female ratio was approx. 3:1 with all patients belonging to high productive age group. Most of the patients reported to the hospital within $24-48$ hrs. Mechanism of injury was mainly due to fall on outstretched hand (66.67\%). Rest (33.33\%) were due to RTA; $23 \%$ cases were intraarticular fractures, $77 \%$ cases were extraarticular. The period of immobilisation ranged from $4-6$ weeks. Mild pain which did not interfere with activities of daily living was present in 35\% of cases. Restriction of activity in form of activities of weight lifting was present in $33 \%$ cases, of which most of them had radiocarpal and radioulnar intraarticular fracture and in most of the cases anatomically slight dorsal tilt was there.

Residual deformity in form of prominent ulnar styloid, residual dorsal tilt, radial deviation of hand was present in $33 \%$ cases, of which most of them had radiocarpal and radioulnar intraarticular fracture and in most of the cases anatomically slight dorsal tilt was there. Range of movements were good in $90 \%$ of cases at 6 months followup. Only 3 cases had restricted movements, of these 2 had severe type VIII injury and 1 had type 1 with residual dorsal tilt.

Complication rate was relatively less with 5 patients suffering from finger joint stiffness, no patient had any nerve complication. None of the patients suffered from posttraumatic arthritic changes.

Functional end results were excellent or good in $90 \%$ cases, fair in $3.3 \%$ and poor in $6.6 \%$ cases. Anatomical end result was excellent or good in $90 \%$ cases, fair or poor in $10 \%$ cases and these were intraarticular fractures. Loss of radial length and intraarticular fracture were associated with fair or poor result.

In this study, it was seen that in majority of cases functional and anatomical outcome with close reduction under C-arm and slab treatment with proper way is excellent or good. But cases having intraarticular fracture and radioulnar joint disruption have fair or poor outcome. Moreover, in cases in which anatomical reduction cannot be reached by closed methods, other modalities of treatment should be intervened as good functional outcome is directly related to proper anatomical reduction.

The range of motion at 6-month followup in conservative with respect to palmar flexion, dorsiflexion, supination, pronation, radial deviation, ulnar deviation were $65.33 \pm 6.26$, $67.33 \pm 7.16,66.67 \pm 4.12,61.87 \pm 5.63,18.93 \pm 3.61,17.2 \pm 3.91$ respectively. While in the JESS group the palmar flexion, dorsiflexion, supination, pronation, radial deviation, ulnar deviation were $62.47 \pm 10.50,65.2 \pm 10.83,62.13 \pm 10.09$, $57.67 \pm 14.37,17.33 \pm 5.30,15.73 \pm 3.45$. By comparing the two groups, the range of movement at 6 months followup did not show any statistical significance, which indicates that both the modalities of treatment brought similar result in long term.

The radiological measurements were done and the mean \pm S.D. was computed. The radial height of $10.15 \pm 1.85$ was noted in Jess group, while dorsal angle, radial angle were found to be $3.40 \pm 3.20$ and $17.07 \pm 6.26$ respectively, but the 
conservative had better results as the radial height came out to be $11.13 \pm 3.44$, while dorsal angle and radial angle were 3.86 $\pm 3.20,18.13 \pm 4.75$ indicating better results with conservative group. The results were statistically not significant.

\section{Observation}

\begin{tabular}{|c|c|c|}
\hline Frykman Type & No. of Cases & \% \\
\hline I & 7 & $23.3 \%$ \\
\hline II & 10 & $33.3 \%$ \\
\hline III & 2 & $6.6 \%$ \\
\hline IV & 1 & $3.3 \%$ \\
\hline V & 6 & $20.0 \%$ \\
\hline VI & -- & -- \\
\hline VII & 1 & $3.3 \%$ \\
\hline VIII & 3 & $10.0 \%$ \\
\hline Total Table 1. Fracture Classification \\
\hline \multicolumn{2}{|c|}{} \\
\hline
\end{tabular}

\begin{tabular}{|c|c|c|}
\hline Treatment Given & No. of Cases & $\mathbf{\%}$ \\
\hline Slab & 15 & $50 \%$ \\
\hline JESS & 15 & $50 \%$ \\
\hline Total & $\mathbf{3 0}$ & $\mathbf{1 0 0} \%$ \\
\hline \multicolumn{2}{|c|}{ Table 2. Treatment Given } \\
\hline
\end{tabular}

\begin{tabular}{|c|c|c|}
\hline Period of Immobilisation & No. of Cases & \% \\
\hline 5 weeks & 13 & $43.33 \%$ \\
\hline 6 weeks & 17 & $56.67 \%$ \\
\hline \multicolumn{2}{|c|}{ Table 3. Period of Immobilisation } \\
\hline
\end{tabular}

\begin{tabular}{|c|c|c|}
\hline X-Rays & No. of Cases & $\%$ \\
\hline \multicolumn{3}{|c|}{ Dorsal Angle } \\
\hline $11-14$ & 7 & $23.33 \%$ \\
\hline$>15$ & 2 & $6.67 \%$ \\
\hline Volar/neutral angle & 13 & $43.33 \%$ \\
\hline Total & $\mathbf{3 0}$ & $26.66 \%$ \\
\hline $19-25$ & 8 & $\mathbf{1 0 0 \%}$ \\
\hline $13-18$ & 9 & $26.67 \%$ \\
\hline $8-12$ & 7 & $30 \%$ \\
\hline$<7$ & 6 & $23.33 \%$ \\
\hline Total & $\mathbf{3 0}$ & $\mathbf{1 0 0 \%}$ \\
\hline \multicolumn{3}{|c|}{ Radial Angle } \\
\hline $10-14 \mathrm{~mm}$ & 10 & $33.33 \%$ \\
\hline $5-9 \mathrm{~mm}$ & 9 & $30 \%$ \\
\hline $0-4 \mathrm{~mm}$ & 11 & $36.67 \%$ \\
\hline$<0 \mathrm{~mm}$ & 0 & -- \\
\hline Total & 30 & $100 \%$ \\
\hline Table 4. Initial Roentgenograph (Pre-Reduction X-Rays) \\
\hline
\end{tabular}

\begin{tabular}{|c|c|c|}
\hline Subjective & No. of Cases & \% \\
\hline Pain & 11 & $36.6 \%$ \\
\hline Stiffness & 8 & $26.6 \%$ \\
\hline Swelling & 3 & $10 \%$ \\
\hline \multicolumn{3}{|c|}{ Table 5. Followup } \\
\hline
\end{tabular}

\begin{tabular}{|c|c|c|}
\hline Residual Deformity & No. of Cases & \% \\
\hline Prominence of ulnar styloid & 6 & $20 \%$ \\
\hline Residual dorsal tilt & 9 & $30 \%$ \\
\hline Radial deviation of hand & 2 & $6.6 \%$ \\
\hline \multicolumn{2}{|c|}{ Table 6. Followup Objective } \\
\hline
\end{tabular}

\begin{tabular}{|c|c|c|}
\hline Movements & No. of Cases & $\%$ \\
\hline Dorsiflexion $>45$ & 28 & $93.33 \%$ \\
\hline$<45$ & 2 & $6.67 \%$ \\
\hline Total & 30 & $100 \%$ \\
\hline Palmar flexion > 30 & 28 & $93.33 \%$ \\
\hline$<30$ & 2 & $6.67 \%$ \\
\hline Total & 30 & $100 \%$ \\
\hline Ulnar deviation > 15 & 21 & $70 \%$ \\
\hline$<15$ & 9 & $30 \%$ \\
\hline Total & 30 & $100 \%$ \\
\hline Radial deviation $>15$ & 23 & $76.67 \%$ \\
\hline$<15$ & 7 & $23.33 \%$ \\
\hline Total & 30 & $100 \%$ \\
\hline Supination $>50$ & 28 & $93.33 \%$ \\
\hline$<50$ & 2 & $6.67 \%$ \\
\hline Total & 30 & $100 \%$ \\
\hline Pronation $>50$ & 27 & $90 \%$ \\
\hline$<50$ & 3 & $10 \%$ \\
\hline Total & 30 & $100 \%$ \\
\hline Circumduction + & 26 & $86.67 \%$ \\
\hline- & 4 & $13.33 \%$ \\
\hline Total & 30 & $100 \%$ \\
\hline \multicolumn{3}{|c|}{ Table 7. Followup Objective } \\
\hline
\end{tabular}

\begin{tabular}{|l|c|c|}
\hline & No. of Cases & $\%$ \\
\hline Decreased grip strength & 3 & $10 \%$ \\
\hline \multicolumn{2}{|c|}{ Table 8. Followup } \\
\hline
\end{tabular}

\begin{tabular}{|c|c|c|}
\hline & No. of Cases & \% \\
\hline Finger joint Stiffness & 3 & $10 \%$ \\
\hline \multicolumn{2}{|c|}{ Table 9. Followup } \\
\hline
\end{tabular}

\begin{tabular}{|c|c|c|}
\hline X-Rays & No. of Cases & \% \\
\hline Dorsal Angle & & \\
\hline $1-10$ & 9 & $30 \%$ \\
\hline $11-14$ & 0 & -- \\
\hline$>15$ & 0 & -- \\
\hline Volar/Neutral Angle & 21 & $70 \%$ \\
\hline Total & $\mathbf{3 0}$ & $\mathbf{1 0 0 \%}$ \\
\hline Radial Angle & & \\
\hline $19-23$ & 11 & $36.67 \%$ \\
\hline $13-18$ & 13 & $43.33 \%$ \\
\hline $8-12$ & 5 & $16.67 \%$ \\
\hline$<7$ & 1 & $3.33 \%$ \\
\hline Total & $\mathbf{3 0}$ & $\mathbf{1 0 0 \%}$ \\
\hline Radial Length & & \\
\hline $10-13 \mathrm{~mm}$ & 11 & $36.67 \%$ \\
\hline $5-9 \mathrm{~mm}$ & 17 & $43.33 \%$ \\
\hline $0-4 \mathrm{~mm}$ & 2 & $6.67 \%$ \\
\hline$<0 \mathrm{~mm}$ & -- & -- \\
\hline Total & $\mathbf{3 0}$ & $\mathbf{1 0 0} \%$ \\
\hline
\end{tabular}

Table 10. Final Roentgenograph Findings, i.e. at 6 Months

\begin{tabular}{|c|c|c|}
\hline Functional End Results & No. of Cases & $\mathbf{\%}$ \\
\hline Excellent & 18 & $60 \%$ \\
\hline Good & 8 & $26.67 \%$ \\
\hline Fair & 2 & $6.67 \%$ \\
\hline Poor & 2 & $6.67 \%$ \\
\hline Total & 30 & $100 \%$ \\
\hline Table 11. Results Functional End Results \\
\hline
\end{tabular}

$86.67 \%$ of cases had excellent and good results, $6.67 \%$ had fair result and $6.67 \%$ had poor result. 


\begin{tabular}{|c|c|c|}
\hline Anatomical End Results & No. of Cases & $\mathbf{\%}$ \\
\hline Excellent & 11 & $36.67 \%$ \\
\hline Good & 16 & $53.33 \%$ \\
\hline Fair & 2 & $6.67 \%$ \\
\hline Poor & 1 & $3.33 \%$ \\
\hline Total & $\mathbf{3 0}$ & $\mathbf{1 0 0} \%$ \\
\hline Table 12. Results Anatomical End Results \\
\hline \multicolumn{2}{|l}{}
\end{tabular}

Case No. 01
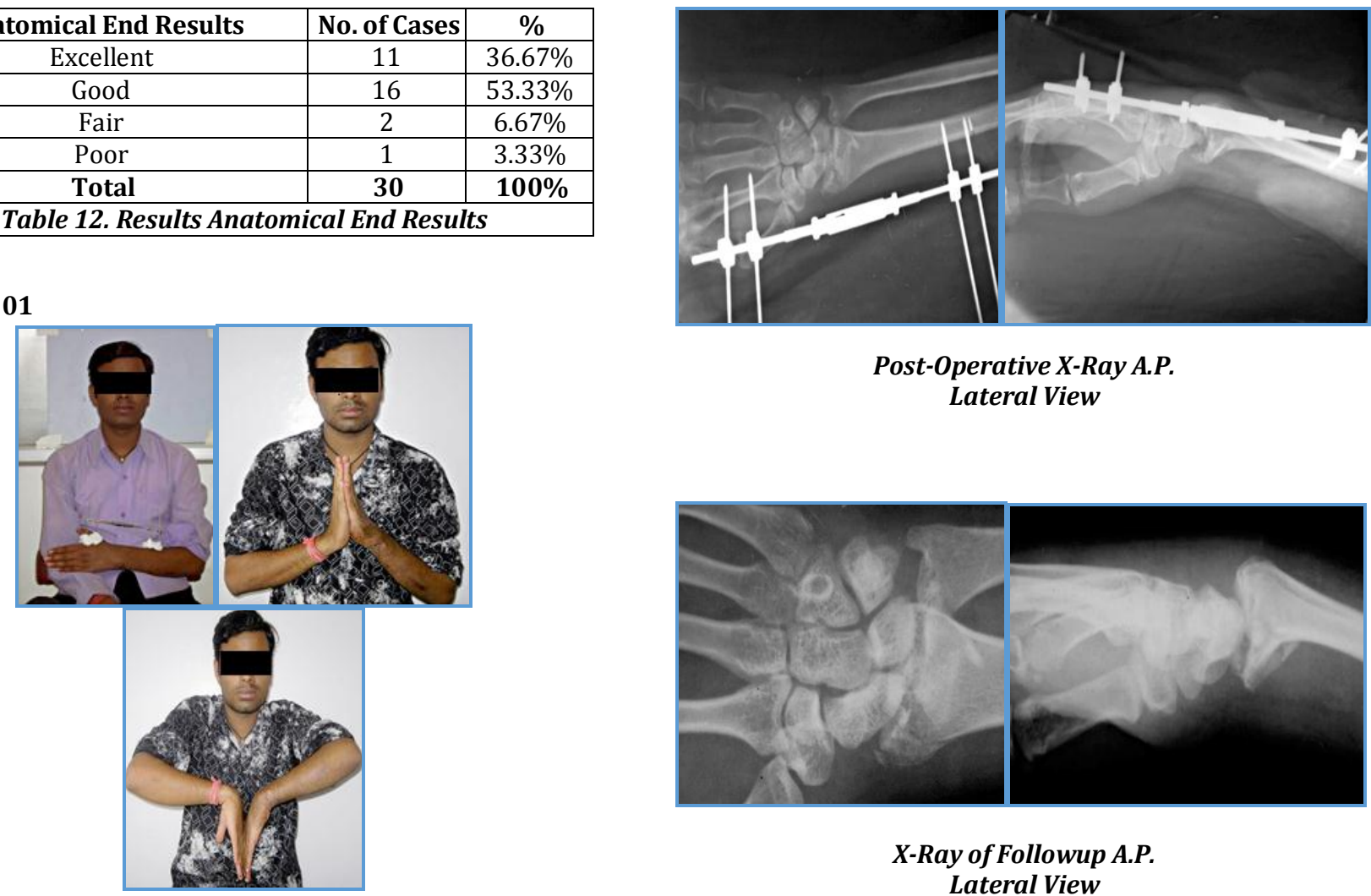

Post-Operative X-Ray A.P. Lateral View

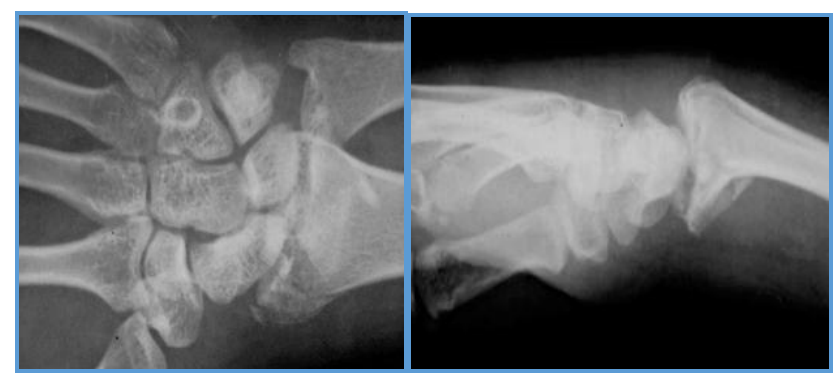

X-Ray of Followup A.P. Lateral View

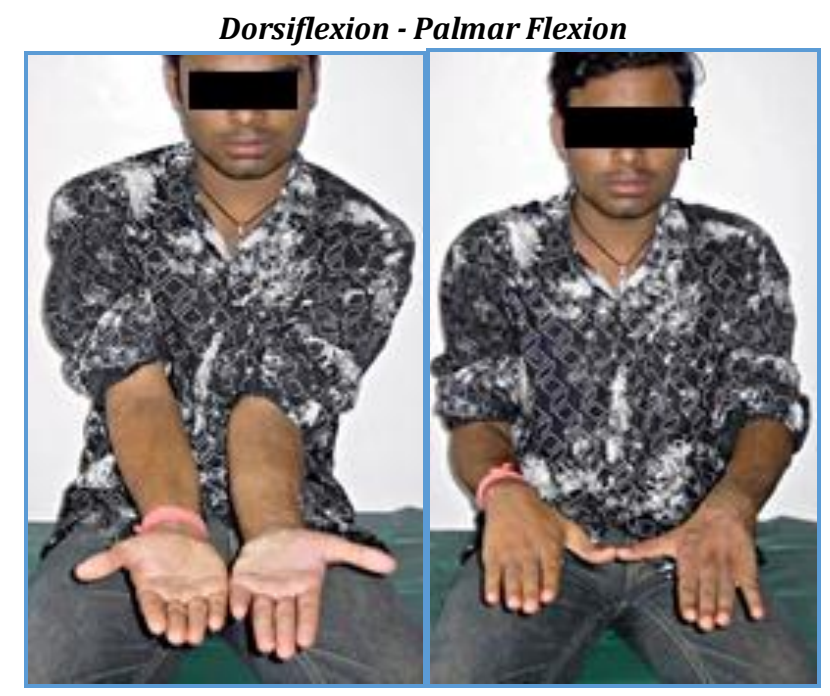

Case No. 2

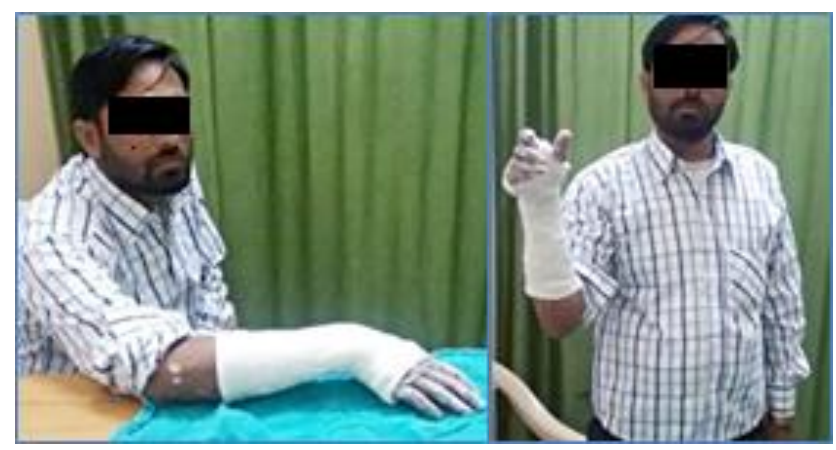

Supination Pronation
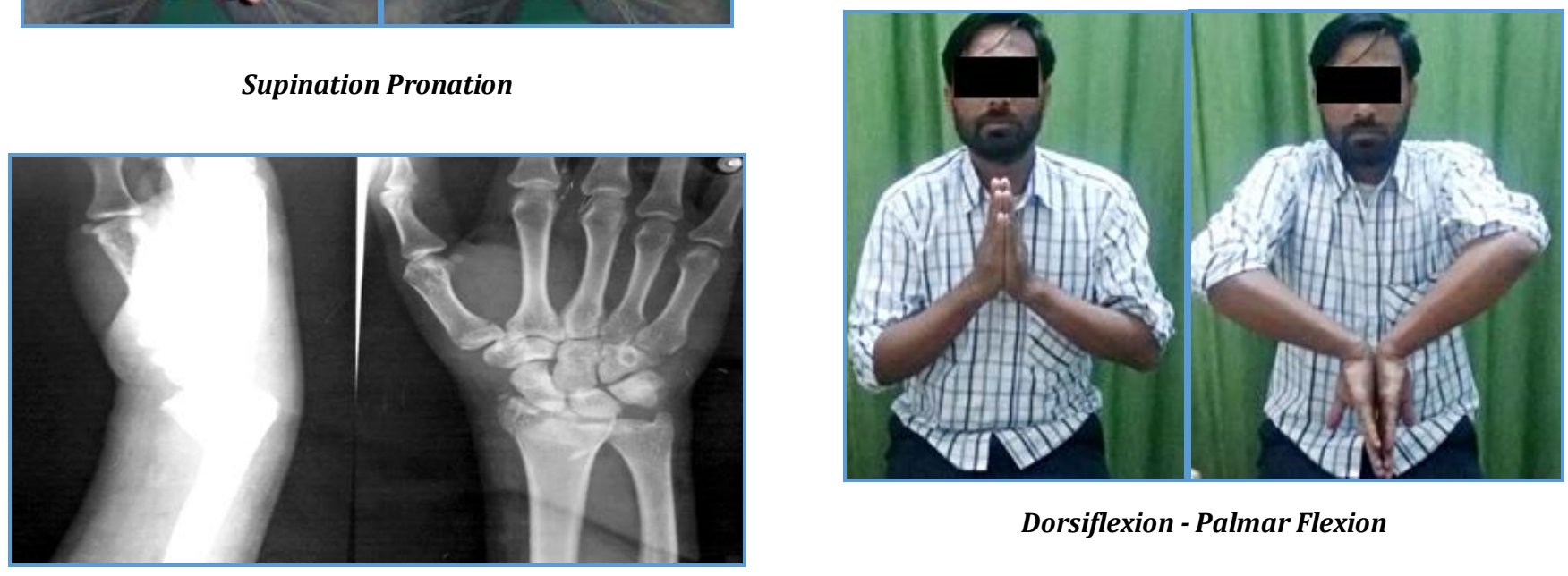

Dorsiflexion - Palmar Flexion

Pre-Operative 

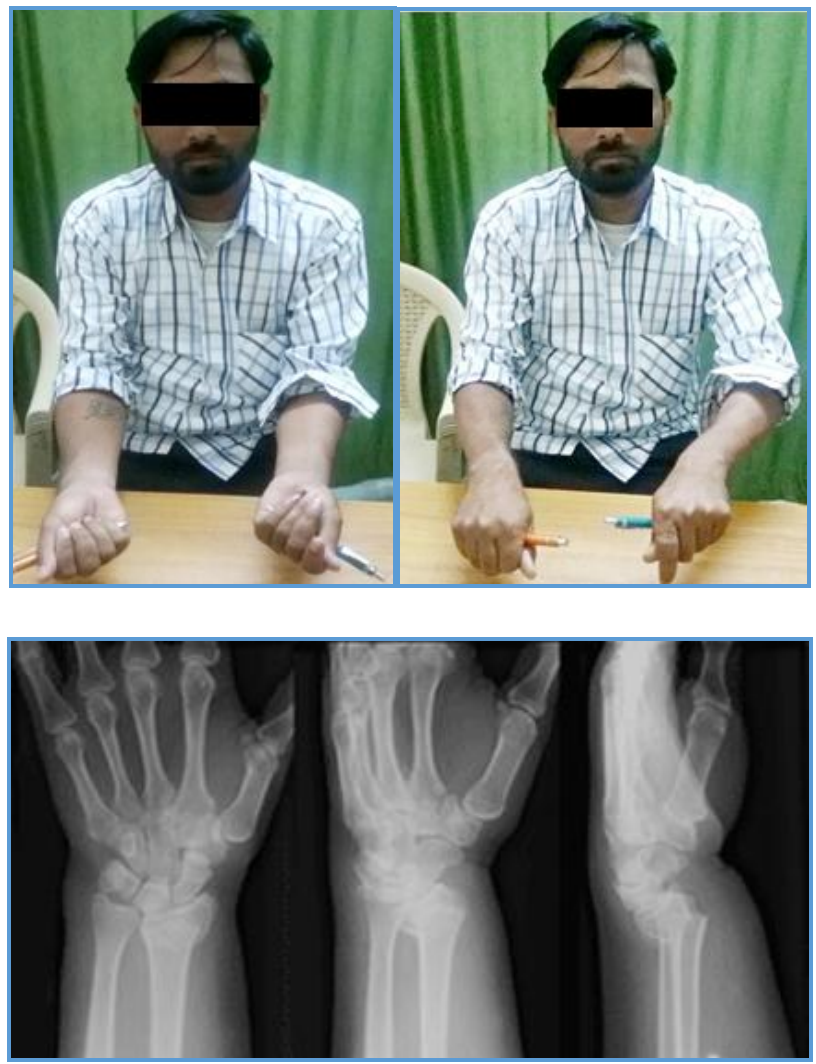

X-Ray Pre-reduction Type-1

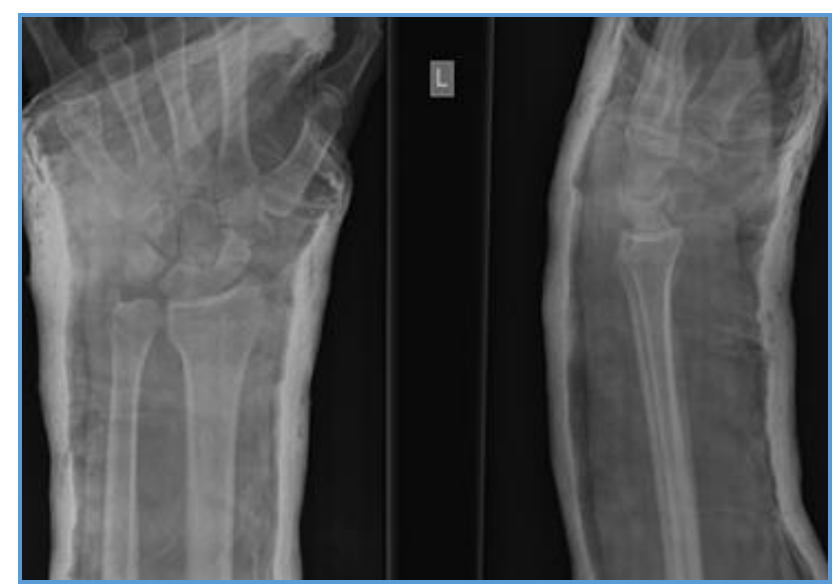

X-Ray Post-reduction Type-1
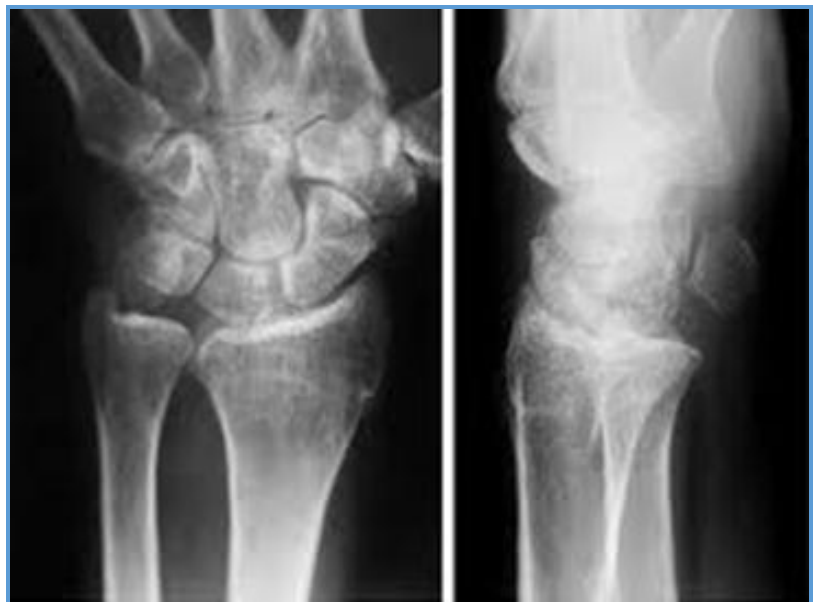

X-Ray after 6 Months Post Reduction Type-1

\section{DISCUSSION}

The degree of disability after a distal radius fracture has been shown to correlate with the amount of residual deformity.[7] There are three important components of this fracture.[1-4]

1. The dorsal tilt - A comparable and apparently satisfactory reduction was carried out in all group as far as this component was concerned.

2. The normal inward tilt of the distal end of the radius The behaviour of this component followed a pattern identical to that of a residual dorsal tilt. A certain amount of correction was obtained at the time of reduction.

3. Radial shortening - In the present study, the loss of radial length in pre-reduction films was $4 \mathrm{~mm}$ (Radial length $7 \mathrm{~mm}$ avg.) and in followup studies loss was $2.5 \mathrm{~mm}$ (radial length $=8.5 \mathrm{~mm}$ avg.) the significant observation was that in the cases which had fair or poor results, nearly all had loss of $7 \mathrm{~mm}$ or more of radial length.

Function as reflected by grip strength and endurance was impaired when the fracture healed with a dorsal angulation of the distal articular surface of greater than $20^{\circ}$ with shortening defined as a loss of radial inclination of $10^{\circ}$ or greater and with radial shift of the distal fragment beyond 2 $\mathrm{mm}$. Radial shortening was found to be associated with disruption or the distal radioulnar joint in several instances.

In the present series, $30 \%$ cases had dorsal tilt; $20 \%$ had loss of radial angle by $10^{\circ}$ or more did not have much impact on final outcome in this series, but the loss of radial length resulted in fair or poor outcome. There were very few complications in this series. Only 3 patients suffered from finger joint stiffness and none had symptoms of carpal tunnel syndrome or other nerve complication.

None of the patients suffered from arthritic changes, presumably this could be because of insufficient number of cases of intra-articular fractures and short followup (6 months). It appeared from the above study that degree of deformity does correlate with the amount of disability.

\section{REFERENCES}

[1] Jupiter JB, Lipton $H$. The operative treatment of intraarticular fractures of the distal radius. Clin orthop 1993;292:48-61.

[2] Wakefield AE, McQueen MM. The role of physiotherapy and clinical predictors of outcome after fracture of the distal radius. J Bone Joint surg 2000;82(7):972-6.

[3] Colles A. On the fracture of the carpal extremity of the radius. Edinburgh Med Surg J 1814;10:181. Clin Orthop Relat Res 2006;445:5-7.

[4] Barton JR. views and treatment of an important injury to the wrist. Med Examiner 1838;1:365.

[5] Smith RW. A treatise on fractures in the vicinity of joints and on certain forms of accidental and congenital dislocations. Dublin: Hodges and Smith 1847;p 162.

[6] Frykman G. Fracture of the distal radius including sequelae-shoulder hand finger syndrome, disturbance in the distal radio-ulnar joint and impairment of nerve function. A clinical and experimental study. Acta Ortho Scand Suppl 1967;108:3.

[7] Sarmiento A, Pratt GW, Berry NC, et al. Colles fractures. Functional bracing in supination. J Bone surg 1975;57(3):311-7. 


\section{Jemds.com}

[8] Green DP. Pins and plaster treatment of comminuted fractures of the distal end of the radius. J Bone joint surg 1975;57(3):304-10.

[9] Knirk JL, Jupiter JB. Intra-articular fractures of the distal end of the radius in young adults. J Bone Joint surg 1986;68(5):647-59.

[10] Handoll HH, Madhok R. Surgical interventions for treating distal radial fractures in adults. Cochrane Database Syst Rev 2003;3:CD003209.

[11] Leone J, Bhandari M, Adili A, et al. Predictors of early and late instability following conservative treatment of extra-articular distal radius fractures. Arch Orthop Trauma Surg 2004;124(1):38-41.

\section{Original Research Article}

[12] Fernandez DL. Closed manipulation and casting of distal radius fractures. Hand Clin 2005;21(3):307-16.

[13] Mackenney PJ, McQueen MM, Elton R. Prediction of instability in distal radial fractures. J Bone Joint Surg Am 2006;88(9):1944-51.

[14] Chung KC, Watt AJ, Kotsis SV, et al. Treatment of unstable distal radial fractures with the volar locking plate system. J Bone Joint Surg Am 2006;88(12):268794.

[15] Blakeney WG. Stabilization and treatment of colles fractures in elderly patients. Clin Interv Aging 2010;5:337-44. 